\title{
Can the upper esophageal sphincter contractile integral help classify achalasia?
}

\author{
Tania Triantafyllou a , Charalampos Theodoropoulos ${ }^{a}$, Apostolos Mantides ${ }^{b}$, Demosthenis Chrysikos ${ }^{a}$, \\ Spyridon Smparounis ${ }^{a}$, Konstantinos Filis ${ }^{a}$, Georgios Zografos ${ }^{a}$, Dimitrios Theodorou ${ }^{a}$
}

Hippocration General Hospital; Private Practice, Athens, Greece

\section{Abstract}

\begin{abstract}
Background The use of high-resolution manometry (HRM) in achalasia patients has revealed abnormal findings concerning upper esophageal sphincter (UES) function. The introduction of the UES contractile integral (UES-CI), as with the distal contractile integral (DCI), may complement the interpretation of the manometric study of achalasia subtypes, defined by the Chicago Classification v3.0.
\end{abstract}

Methods Patients were classified into achalasia subtypes based on HRM. UES length $(\mathrm{cm})$, UES resting pressure $(\mathrm{mmHg})$, and UES residual pressure $(\mathrm{mmHg})$ were recorded. UES-CI $(\mathrm{mmHg} \cdot \mathrm{sec} \cdot \mathrm{cm})$ was calculated in a manner similar to that used for the DCI measurement at rest (landmark CI), corrected for respiration, and its relation to achalasia subtypes was evaluated.

Results Twenty-four achalasia patients with mean age 55.29 years were included. Of these, $16.6 \%$ $(n=4)$ were diagnosed with achalasia type I, 58.3\% $(n=14)$ with type II, and 25\% $(n=6)$ with type III. The landmark UES-CI, mean UES-CI, UES-CI corrected for respiration, and UES resting pressure were found to be significantly higher among patients with achalasia type II compared to the other types ( 1768.9 vs. $677.1, \mathrm{P}=0.03 ; 1827.1$ vs. $3555.1, \mathrm{P}=0.036 ; 174.2$ vs. $72.8, \mathrm{P}=0.027$; and 108.1 vs. $55.8, \mathrm{P}=0.009$, respectively).

Conclusions We introduce the CI index as a tool for the manometric evaluation of the UES in achalasia. UES resting pressure, landmark UES-CI and mean UES-CI were significantly higher in achalasia patients with panesophageal pressurization compared to types I and III. This finding may reflect a protective reaction against the risk of aspiration in this group, but further studying and clinical correlation is required.

Keywords Achalasia, contractile integral, high resolution manometry, upper esophageal sphincter Ann Gastroenterol 2018; 31 (4): 1-6

\section{Introduction}

High-resolution manometry (HRM) elucidates esophageal motility disorders via software analysis. The use of novel manometric measurements that constitute the Chicago

${ }^{\text {a}}$ Foregut Surgery Department, $1^{\text {st }}$ Propaedeutic Surgical Clinic, Hippocration General Hospital Athens (Tania Triantafyllou, Charalampos Theodoropoulos, Demosthenis Chrysikos, Spyridon Smparounis, Konstantinos Filis, Georgios Zografos, Dimitrios

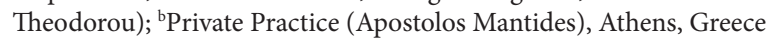

Conflict of Interest: None

Correspondence to: Tania Triantafyllou, MD, 114 Vas. Sofias Av., 11527 Athens, Greece, e-mail: t_triantafilou@yahoo.com

Received 16 October 2017; accepted 2 April 2018; published online 3 May 2018

DOI: https://doi.org/10.20524/aog.2018.0270
Classification (CC) was recently expanded to the 3.0 version. Disorders that involve esophagogastric junction (EGJ) outflow obstruction are further classified into achalasia subtypes and EGJ outflow obstruction. Further, achalasia is defined by the presence of elevated integrated relaxation pressure and is divided into subtypes according to the different patterns of non-peristaltic esophageal pressurization [1].

Manometric profiles of the lower esophageal sphincter (LES) have been widely studied and are commonly used in several definitions of dysmotilities of the esophagus mentioned in CC v3.0. Calculated as amplitude $\times$ duration $\times$ length $(\mathrm{mmHg} \cdot \mathrm{sec} \cdot \mathrm{cm})$ of the distal esophageal contraction exceeding $20 \mathrm{mmHg}$ from the transition zone to the proximal margin of the LES, the distal contractile integral (DCI) has the potential to represent the contractile vigor of a specific region and has been widely established in the currently used format of HRM reports [1]. Recent publications introduce the EGJ-contractile integral (EGJ-CI), defined similarly to 
the DCI, as a more representative tool for evaluating the complex anatomy of the EGJ barrier in patients with achalasia and gastroesophageal reflux disease (GERD) before and after surgery, in patients off proton pump inhibitor therapy undergoing ambulatory $\mathrm{pH}$ monitoring, in non-responders to proton pump inhibitors, and among patients with abnormal acid exposure [2-4].

On the other hand, the utility of manometric analysis of the upper esophageal sphincter (UES) is not yet widely recognized. In fact, the CC does not use UES metrics in any dysmotility definition. Nevertheless, analysis of the UES could become mandatory in the future in terms of evaluation of esophageal deglutitive abnormalities, as it may play a key role in predicting the response to treatment. For instance, according to retrospective studies, abnormal UES parameters (most commonly hypertensive UES) among achalasia patients were associated with a lack of response to treatment $[5,6]$. Moreover, UES metrics were significantly decreased after balloon dilation in type II achalasia patients [7].

Manometry of the pharynx and the UES outlines the swallowing mechanism, reflecting both relaxation and closure of these anatomical structures. UES resting and residual pressures are the only measurements of the UES presented in the currently used HRM analysis [8]. However, asymmetry of the UES may require more detailed interpretation, mainly in the field of investigation of motility disorders of the esophagus. Application of the contractile integral index to the manometric profile of the UES may improve comprehension of the function of this sphincter, especially with regard to abnormal manometric studies such as those in patients with achalasia.

The aim of this study was to evaluate the possible association between the manometric profile of the UES and the subtypes of achalasia as defined by the CC, and to introduce the contractile integral of the UES (UES-CI), a parameter that precisely represents the peculiar anatomy and function of the UES in abnormal HRM tests.

\section{Patients and methods}

Patients manometrically diagnosed with achalasia from August 2015 to March 2016 were studied prospectively and their HRM analyses were reviewed retrospectively. Demographic data (age, sex) were collected. Based on a detailed medical history, any individual who had previously been treated either endoscopically or surgically for achalasia was excluded from the study. Patients included were $>18$ years old. All patients underwent HRM and were classified into achalasia subtypes according to $\mathrm{CC}$ v3.0. The relation between achalasia subtypes and manometric features was evaluated (see below for details). Additionally, we divided the patients into two subgroups of comparable size in order to compare their HRM characteristics: one group represented patients with type II achalasia and the other included patients with other types.

We also conducted the same measurements among a group of adult patients diagnosed with GERD and completed a case- control analysis between achalasia and GERD patients. None of these patients had any previous endoscopic or surgical history of the upper gastrointestinal tract.

\section{HRM technique and analysis}

HRM was performed after a 6-h fasting. A catheter with an outer diameter of $4 \mathrm{~mm}$ and 36 circumferential sensors spaced at $1 \mathrm{~cm}$ intervals (ManoScan ${ }^{360}$ High Resolution Manometry System, Sierra Scientific Instruments, Los Angeles, CA) was positioned below the EGJ through an anesthetized nasal canal. The system was calibrated to record pressures between -20 and $600 \mathrm{mmHg}$ and data were collected at a sampling rate of $50 \mathrm{~Hz}$ (ManoScan Data Acquisition, Sierra Scientific Instruments). After a 30-sec period without swallowing in order to evaluate UES basal pressure (landmark), 10 wet swallows of $5 \mathrm{~mL}$ were applied in supine position.

HRM analysis was conducted using the ManoView software (Sierra Scientific Instruments). UES length $(\mathrm{cm})$, UES resting pressure $(\mathrm{mmHg})$ and UES residual pressure $(\mathrm{mmHg})$ were recorded for each case. In addition to the standard HRM report, the UES-CI $(\mathrm{mmHg} \cdot \mathrm{sec} \cdot \mathrm{cm})$ was calculated similarly to the DCI. The resting UES-CI (landmark CI) was calculated for three consecutive respiratory cycles as the total number of units of $\mathrm{mmHg} \cdot \mathrm{sec} \cdot \mathrm{cm}$ greater than $20 \mathrm{mmHg}$ from the upper limit of the UES to the lower limit of the LES minus the total CI below the lower limit of the UES (Fig. 1). UES pressure is a robust manometric feature with respiratory variation. Therefore, the values were divided by the duration of the three respiratory cycles and CI was corrected for respiration (CI corrected for respiration in $\mathrm{mmHg} \cdot \mathrm{cm}$ ). Mean CI was calculated as the mean value of the corrected CI of 10 wet swallows of each study starting $5 \mathrm{sec}$ before UES relaxation and lasting for another $10 \mathrm{sec}$ (Fig. 2).

\section{Statistical analysis}

The SPSS software package (Version 23.0, IBM Corp., Armonk, NY) was employed for statistical analysis. All variables included in our statistical analysis were quantitative. Data were recorded as mean values \pm standard deviation. Two-tailed $t$-tests were used to determine the significance of the difference between the two groups of patients described above. P-values lower than 0.05 were considered statistically significant.

\section{Results}

Twenty-four consecutive adult patients (11 females, 13 males; mean age 55.29 years, range $19-86$ ) were diagnosed with achalasia based on at least one HRM study between August 2015 and March 2016. Four patients were classified as achalasia type I; 14 as type II; and six as achalasia type III. We 


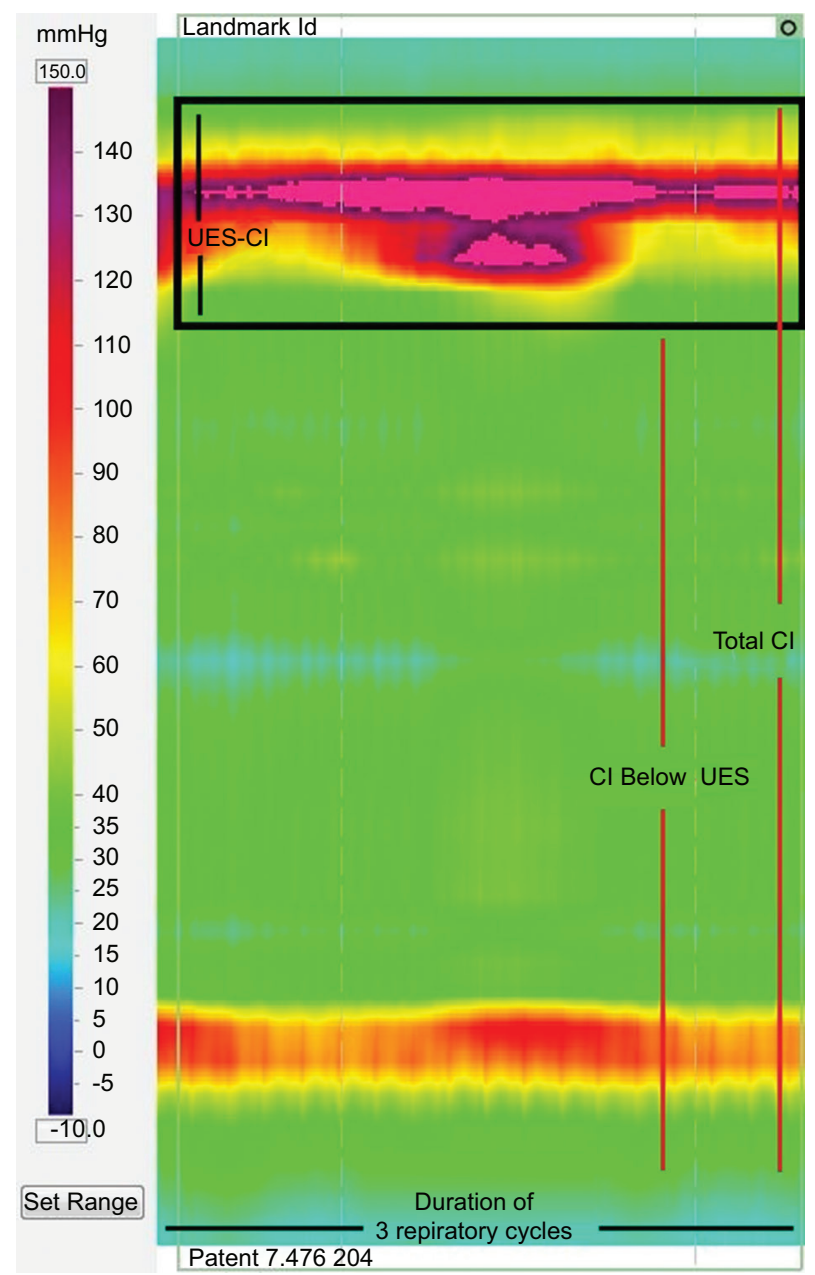

Figure 1 Calculation window for measurement of the upper esophageal sphincter (UES) contractile-integral (UES-CI) during landmark measurement. The UES-CI box (mmHg.sec.cm) includes the integral from the proximal limit of the UES to the distal point of the sphincter for three consecutive respiratory cycles (corrected for respiration)

Table 1 (A) Characteristics of patients with achalasia patients $(n=24)$

\begin{tabular}{lc}
\hline Characteristic & Value \\
\hline Sex & $11(45.8)$ \\
Female (\%) & $13(54.1)$ \\
Male (\%) & $55.2(19-86)$ \\
Mean age in years (range) & \\
Achalasia subtype & $4(16.6)$ \\
Type I (\%) & $14(58.3)$ \\
Type II (\%) & $6(25)$ \\
Type III (\%)
\end{tabular}

separated the patients with achalasia into two subgroups of comparable size: one group of patients with achalasia type II $(n=14)$ and another group of patients with other types $(n=10)$. Patients' characteristics are presented in Table 1A.

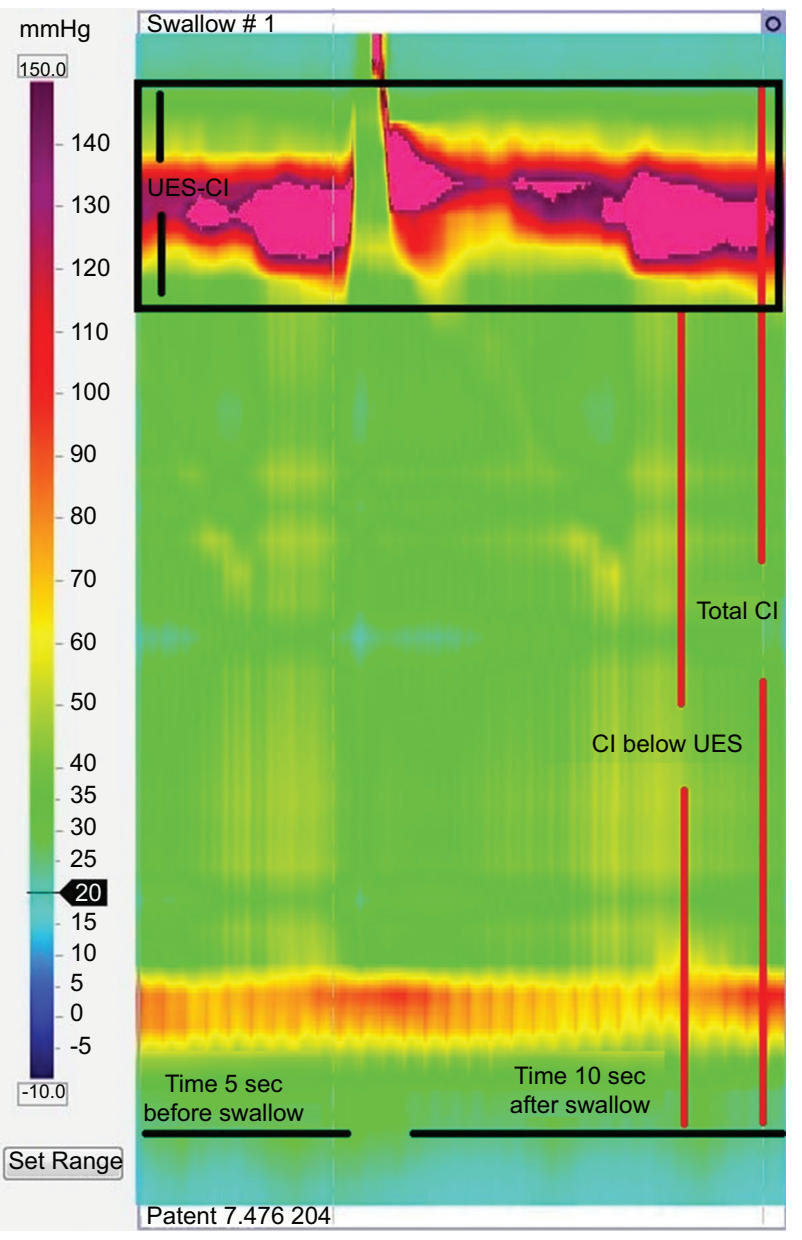

Figure 2 Measurement of the upper esophageal sphincter (UES) contractile-integral (UES-CI) for a separate swallow. The UES-CI box $(\mathrm{mmHg} \cdot \mathrm{sec} \cdot \mathrm{cm})$ is positioned from the proximal to the distal limit of the UES for a total time extending from $5 \mathrm{sec}$ before to $10 \mathrm{sec}$ after the swallow, including the duration of UES relaxation and contraction

Patients in group II had significantly higher mean values of landmark CI compared to those in other groups (1768.9 vs. 677.1, $\mathrm{P}=0.03$ ). Likewise, the mean $\mathrm{CI}$ and corrected CI measurements were significantly higher in group II (mean values 1827.1 vs. $3555.1, \mathrm{P}=0.036$, and 174.2 vs. $72.8, \mathrm{P}=0.027$, respectively). Another parameter that reached statistical significance was the UES resting pressure (mean values in type II 108.1 vs. 55.8 in non-type II patients, $\mathrm{P}=0.009$ ). All other measurements (UES length, UES residual pressure) showed no significant difference between the two groups (Table 2).

We also enrolled 24 GERD patients (15 females, 9 males; mean age 56.12 years, range 22-80) as a control group (Table 1B). Demographic characteristics were similar among the two groups regarding age and sex. Mean UES resting pressure of the control group was $99.9 \mathrm{~mm} \mathrm{Hg}$, mean UES residual pressure was $3.7 \mathrm{~mm} \mathrm{Hg}$, mean landmark CI of the UES was $1397.9 \mathrm{mmHg} \cdot \mathrm{sec} \cdot \mathrm{cm}$, mean landmark CI corrected for respiration was $166.4 \mathrm{mmHg} \cdot \mathrm{cm}$ and mean UES-CI was $2286.8 \mathrm{mmHg} \cdot \mathrm{sec} \cdot \mathrm{cm}$ (Table 3 ). 
Table 1 (B) Characteristics of patients with gastroesophageal reflux disease $(n=24)$

\begin{tabular}{lc}
\hline Characteristic & Value \\
\hline Sex & $15(62.5)$ \\
Female (\%) & $9(37.5)$ \\
Male (\%) & $56.1(22-80)$ \\
\hline
\end{tabular}

Table 2 HRM parameters of the UES among achalasia subtypes

Achalasia subtype $(\mathrm{n}=24)$

\begin{tabular}{lccc}
\hline $\begin{array}{l}\text { HRM features } \\
(\text { mean })\end{array}$ & $\begin{array}{l}\text { II } \\
(\mathrm{n}=14)\end{array}$ & Non II $(\mathrm{n}=10)$ & P-value \\
\hline $\begin{array}{l}\text { Landmark CI } \\
\text { (mmHg.s.cm) }\end{array}$ & 1768.9 & 677.1 & $0.03^{*}$ \\
\hline $\begin{array}{l}\text { Corrected CI } \\
\text { (mmHg.cm) }\end{array}$ & 174.2 & 72.8 & $0.027^{*}$ \\
\hline $\begin{array}{l}\text { Mean CI } \\
\text { (mmHg.sec.cm) }\end{array}$ & 3555.1 & 1827.1 & $0.036^{*}$ \\
\hline UES length $(\mathrm{cm})$ & 3.2 & 3.1 & 0.92 \\
\hline $\begin{array}{l}\text { UES resting } \\
\text { pressure }(\mathrm{mmHg})\end{array}$ & 108.1 & 55.8 & $0.009^{*}$ \\
\hline $\begin{array}{l}\text { UES residual } \\
\text { pressure }(\mathrm{mmHg})\end{array}$ & 14.6 & 9.6 & 0.49 \\
\hline
\end{tabular}

${ }^{*}$ Statistically significant difference $(\mathrm{P}<0.05)$

HRM, high-resolution manometry; CI, contractile integral; UES, upper esophageal sphincter

Table 3 HRM parameters of the UES in the control group (GERD)

\begin{tabular}{lccc}
\hline \multicolumn{3}{c}{ GERD (n=24) } & \\
\hline HRM features & $\begin{array}{l}\text { Median } \\
\text { value }\end{array}$ & Mean value & SD \\
\hline $\begin{array}{l}\text { Landmark CI } \\
\text { (mmHg.sec·cm) }\end{array}$ & 1397.9 & 1584.3 & 1037.7 \\
$\begin{array}{l}\text { Corrected CI } \\
\text { (mmHg.cm) }\end{array}$ & 166.4 & 207.8 & 181.6 \\
$\begin{array}{l}\text { Mean CI } \\
\text { (mmHg.sec.cm) }\end{array}$ & 2260.3 & 2286.8 & 768.9 \\
$\begin{array}{l}\text { UES length (cm) } \\
\begin{array}{l}\text { UES resting } \\
\text { pressure (mmHg) }\end{array}\end{array}$ & 3.95 & 4.3 & 0.8 \\
$\begin{array}{l}\text { UES residual } \\
\text { pressure (mmHg) }\end{array}$ & 96.1 & 99.9 & 61.4 \\
\hline $\begin{array}{l}\text { CI, contractile integral; UES, upper esophageal sphincter; GERD, } \\
\text { gastroesophageal reflux disease; SD, standard deviation }\end{array}$ & 3.6 \\
\hline
\end{tabular}

Case-control analysis between achalasia and GERD patients revealed no statistically significant differences between the two groups apart from UES length, which was greater in GERD patients compared to achalasia patients (mean value 4.3 vs. $3.2, \mathrm{P}<0.001$ ) and UES residual pressure, which was more than four times higher in achalasia patients (mean value 12.5 vs. 3.0, $\mathrm{P}=0.01$ ) (Table 4).

\section{Discussion}

HRM has been established as a sine qua non tool in the field of diagnosis, treatment and follow up of motility disorders of the esophagus. HRM offers the advantage of estimation of the manometric profile of the esophagus by recording color pressure topography plots. Software of the HRM analyzes manometric values for both sphincters and body. The CC, first published in 2009 by the International HRM Working Group and recently expanded and updated in 2014, has gained acceptance worldwide. CC v3.0 elucidates two main categories of motility abnormalities of the esophagus: disorders of the EGJ outflow and disorders of peristalsis [1].

Achalasia is the most common motility disorder of the esophagus with an incidence of 1 case per 100,000 [9]. Weight loss, dysphagia, regurgitation and chest pain are the predominant symptoms of the disease and together compose the Eckardt score. HRM is the gold standard in the diagnosis of achalasia. Based on the patterns of non-peristaltic esophageal pressurization along with elevated values of the integrated relaxation pressure, CC v3.0 classifies achalasia into three subtypes. Type I achalasia is associated with $100 \%$ failed contractions without esophageal pressurization; type II achalasia represents at least $20 \%$ of swallows with panesophageal pressurization; and type III achalasia is followed by at least $20 \%$ of swallows with premature contractions.

Although the combination of HRM with CC has improved the diagnosis of several functional abnormalities of the esophagus, analysis of the UES has been poorly studied so far. In practice, the CC does not include UES characteristics; therefore, there is no disorder in the CC that takes account of the function of the UES [10]. The UES is known as an approximately $3-\mathrm{cm}$ high pressure zone between the pharynx and the proximal esophagus. Pharyngo-esophagogastric function refers to the coordinated pharyngeal and upper esophageal relaxation during swallowing, the manometric reflection of the activity of the striated muscles of the pharynx and cervical esophagus. Although the distal upper gastrointestinal tract consists of smooth muscles, the UES correlates with striated muscle physiology [11]. Threedimensional HRM study of the UES, mainly in healthy patients, revealed a significant variance of UES characteristics and confirmed the asymmetrical pharyngeal anatomy [12]. However, only a few publications have applied UES analysis to abnormal studies. 
Table 4 Case-control analysis (achalasia vs. GERD) of the HRM parameters of the UES

\begin{tabular}{|c|c|c|c|c|c|}
\hline HRM features (mean) & Group & Median & Mean & SD & P-value \\
\hline \multirow[t]{2}{*}{ Landmark CI (mmHg.sec $\cdot \mathrm{cm})$} & Achalasia & 868.90 & 1314.02 & 1237.76 & \multirow[t]{2}{*}{0.41} \\
\hline & GERD & 1397.90 & 1584.34 & 1037.70 & \\
\hline \multirow[t]{2}{*}{ Corrected CI (mmHg.cm) } & Achalasia & 103.25 & 132.00 & 113.11 & \multirow[t]{2}{*}{0.89} \\
\hline & GERD & 166.45 & 207.84 & 181.66 & \\
\hline \multirow[t]{2}{*}{ Mean CI (mmHg.sec.cm) } & Achalasia & 2001.60 & 2835.12 & 2023.31 & \multirow[t]{2}{*}{0.22} \\
\hline & GERD & 2260.30 & 2286.81 & 768.96 & \\
\hline \multirow[t]{2}{*}{ UES length $(\mathrm{cm})$} & Achalasia & 3.00 & 3.20 & 0.63 & \multirow[t]{2}{*}{$<0.001$} \\
\hline & GERD & 3.95 & 4.30 & 0.88 & \\
\hline \multirow[t]{2}{*}{ UES resting pressure $(\mathrm{mmHg})$} & Achalasia & 75.05 & 86.33 & 50.35 & \multirow[t]{2}{*}{0.4} \\
\hline & GERD & 96.10 & 99.91 & 61.45 & \\
\hline \multirow{2}{*}{$\begin{array}{l}\text { UES residual pressure } \\
(\mathrm{mmHg})\end{array}$} & Achalasia & 10.95 & 12.55 & 16.94 & \multirow[t]{2}{*}{0.01} \\
\hline & GERD & 3.70 & 3.06 & 3.64 & \\
\hline
\end{tabular}

* Statistically significant difference $(\mathrm{P}<0.05)$

CI, contractile integral; UES, upper esophageal sphincter; SD, standard deviation; GERD, gastroesophageal reflux disease

HRM interpretation according to the CC provides limited characteristics of the UES. More precisely, mean UES resting pressure, length and mean UES residual pressure are calculated. Lately, there have been a few publications proposing normal values for the pharynx and the UES function in asymptomatic patients [11-14]. Herein, abnormalities such as incomplete relaxation, cricopharyngeal bar, elevated baseline pressure or discoordination between the pharynx and the proximal esophagus may be detected $[15,16]$. It has been assumed that UES abnormalities are more common among patients with achalasia, mainly with regards to hypertension, and this finding may be predictive of a dismal response to treatment $[5,16]$.

Although the aforementioned features provide invaluable information about the UES, estimating the total pressure of a specific area gives a more complete image of the sphincter than the mean values of single pressure points. A study by Mielens et al proposed investigation of the integrity of the UES [17]. DCI is an HRM parameter that integrates time, pressure and distance along the esophagus, from the proximal esophagus to the proximal point of the LES. It is measured by calculating the total surface $>20 \mathrm{mmHg}$ in a specific area of the analysis. As a single number, it may identify both hypercontractility and hypocontractility of the lower esophagus and LES during deglutition. The EGJ-CI, similar to the DCI, was recently introduced in order to assess the EGJ barrier function among patients diagnosed with achalasia or GERD before and after surgery $[2-4,18,19]$. Hoshino et al [3] first presented the adjustment of the DCI to the EGJ (EGJCI) over a 10-sec interval, while Nicodème et al [4] measured the EGJ-CI independently of respiration $2 \mathrm{~mm} \mathrm{Hg}$ above the gastric baseline, correcting for the respiratory cycle and taking account of the crural component and the duration of the respiratory cycle. This appears to be a more representative way of estimating LES contractility, in view of the complex nature of the components of the sphincter, including the diaphragmatic crus $[3,4]$. Gor et al proved that LES-CI calculated for a single respiratory cycle was equally reliable as the metric of Nicodème et al and proposed simplifying the feature [18].

In contrast, our study confirmed that UES function appears to be independent from respiration, as the landmark UESCI was significantly higher in the type-II group of patients compared to the non-type-II group, even before correction for respiration. This can be clearly explained based on the anatomy of the UES. Mean CI and UES resting pressure were also found to be higher in patients with achalasia type II. A possible explanation could be the manometric profile of this type of achalasia. Since panesophageal pressurization may lead to a greater risk of aspiration, high UES pressures in this group during both resting and swallowing could be attributed to a protective mechanism. This hypothesis was also confirmed by the studies of Blais et al and Menezes et al, who concluded that patients diagnosed with achalasia type II present with higher UES residual pressures compared to the other types [20,21]. However, the introduction of the landmark UES-CI may be a more reliable measurement, aiming to eliminate the limitations of the transient calculation of the resting and residual pressures of the UES.

Case-control analysis concluded that UES residual pressure was four times higher in achalasia patients compared to GERD patients ( 12.55 vs. $3.6, \mathrm{P}=0.01)$ and that UES length was smaller among achalasia patients $(3.2$ vs. $4.3, \mathrm{P}<0.001)$. Although the clinical significance of the second finding seems unclear, the values of UES residual pressure could suggest that achalasia patients suffer from a higher risk of aspiration due to incomplete clearance of the esophageal lumen and stasis. In GERD, on the other hand, esophageal clearance is considered to be complete, apart from cases in which impairment of the contractility of the body of the esophagus caused by chronic reflux is diagnosed [22]. 
In this study, we evaluated the UES-CI as a novel tool for evaluating patients diagnosed with achalasia and showed that achalasia type II is associated with greater values of UES-CI compared to the other types. UES resting pressure was also found to be increased among this group of achalasia patients, while UES residual pressure was significantly higher in achalasia patients compared to the control group of GERD patients. UESCI could have the potential to further improve our understanding of UES function in the field of esophageal motility abnormalities. Further prospective studies are mandatory to evaluate the actual clinical application of the UES-CI.

\section{Summary Box}

\section{What is already known:}

- The Chicago Classification elucidates the diagnosis of achalasia subtypes based on high-resolution manometry (HRM)

- Manometric characteristics of the upper esophageal sphincter (UES) have been poorly studied

- HRM measurements of the UES may be of clinical significance in predicting response to treatment of achalasia of the esophagus

- UES residual pressure is significantly higher among patients with achalasia type II compared to the other subtypes

\section{What the new findings are:}

- We introduce the UES contractile integral in HRM analysis of the UES among achalasia and gastroesophageal reflux disease (GERD) patients

- Patients with achalasia type II present with greater values of UES-CI and UES resting pressure compared to the other types

- UES residual pressure is higher in individuals diagnosed with achalasia compared to GERD patients

\section{References}

1. Kahrilas PJ, Bredenoord AJ, Fox M, et al; International High Resolution Manometry Working Group. The Chicago Classification of esophageal motility disorders, v3.0. Neurogastroenterol Motil 2015;27:160-174.

2. Wang D, Patel A, Mello M, Shriver A, Gyawali CP. Esophagogastric junction contractile integral (EGJ-CI) quantifies changes in EGJ barrier function with surgical intervention. Neurogastroenterol Motil 2016;28:639-646.

3. Hoshino M, Sundaram A, Mittal SK. Role of the lower esophageal sphincter on acid exposure revisited with high-resolution manometry. J Am Coll Surg 2011;213:743-750.

4. Nicodème F, Pipa-Muniz M, Khanna K, Kahrilas PJ, Pandolfino JE. Quantifying esophagogastric junction contractility with a novel HRM topographic metric, the EGJ-Contractile Integral: normative values and preliminary evaluation in PPI non-responders. Neurogastroenterol Motil 2014;26:353-360.

5. Mathews SC, Ciarleglio M, Chavez YH, Clarke JO, Stein E, Chander Roland B. Upper esophageal sphincter abnormalities are strongly predictive of treatment response in patients with achalasia. World $J$ Clin Cases 2014;2:448-454.

6. Chavez YH, Ciarleglio MM, Clarke JO, Nandwani M, Stein E, Roland BC. Upper esophageal sphincter abnormalities: frequent finding on high-resolution esophageal manometry and associated with poorer treatment response in achalasia. J Clin Gastroenterol 2015;49:17-23.

7. Wauters L, van Oudenhove L, Selleslagh M, et al. Balloon dilation of the esophago-gastric junction affects lower and upper esophageal sphincter function in achalasia. Neurogastroenterol Motil 2014;26:69-76.

8. Bhatia SJ, Shah C. How to perform and interpret upper esophageal sphincter manometry. J Neurogastroenterol Motil 2013;19:99-103.

9. Podas T, Eaden J, Mayberry M, Mayberry J. Achalasia: a critical review of epidemiological studies. Am J Gastroenterol 1998;93:2345-2347.

10. Wang YT, Yazaki E, Sifrim D. High-resolution manometry: esophageal disorders not addressed by the "Chicago Classification". J Neurogastroenterol Motil 2012;18:365-372.

11. Silva LC, Herbella FA, Neves LR, Vicentine FP, Neto SP, Patti MG. Anatomophysiology of the pharyngo-upper esophageal area in light of high-resolution manometry. J Gastrointest Surg 2013; 17:2033-2038.

12. Meyer JP, Jones CA, Walczak CC, McCulloch TM. Three-dimensional manometry of the upper esophageal sphincter in swallowing and nonswallowing tasks. Laryngoscope 2016;126:2539-2545.

13. Takasaki K, Umeki H, Enatsu K, et al. Investigation of pharyngeal swallowing function using high-resolution manometry. Laryngoscope 2008;118:1729-1732.

14. Weijenborg PW, Kessing BF, Smout AJ, Bredenoord AJ. Normal values for solid-state esophageal high-resolution manometry in a European population; an overview of all current metrics. Neurogastroenterol Motil 2014;26:654-659.

15. Kwiatek MA, Mirza F, Kahrilas PJ, Pandolfino JE. Hyperdynamic upper esophageal sphincter pressure: a manometric observation in patients reporting globus sensation. Am J Gastroenterol 2009;104:289-298.

16. Chavez YH, Ciarleglio MM, Clarke JO, Nandwani M, Stein E, Roland BC. Upper esophageal sphincter abnormalities: frequent finding on high-resolution esophageal manometry and associated with poorer treatment response in achalasia. J Clin Gastroenterol 2015;49:17-23.

17. Mielens JD, Hoffman MR, Ciucci MR, Jiang JJ, McCulloch TM. Automated analysis of pharyngeal pressure data obtained with high-resolution manometry. Dysphagia 2011;26:3-12.

18. Gor P, Li Y, Munigala S, Patel A, Bolkhir A, Gyawali CP. Interrogation of esophagogastric junction barrier function using the esophagogastric junction contractile integral: an observational cohort study. Dis Esophagus 2016;29:820-828.

19. Tolone S, De Bortoli N, Marabotto E, et al. Esophagogastric junction contractility for clinical assessment in patients with GERD: a real added value? Neurogastroenterol Motil 2015;27:1423-1431.

20. Blais P, Patel A, Sayuk GS, Gyawali CP. Upper esophageal sphincter (UES) metrics on high-resolution manometry (HRM) differentiate achalasia subtypes. Neurogastroenterol Motil 2017;29.

21. Menezes MA, Herbella FA, Patti MG. High-resolution manometry evaluation of the pharynx and upper esophageal sphincter motility in patients with achalasia. J Gastrointest Surg 2015;19:1753-1757.

22. Chen CL, Yi CH, Liu TT. Relevance of ineffective esophageal motility to secondary peristalsis in patients with gastroesophageal reflux disease. J Gastroenterol Hepatol 2014;29:296-300. 